\title{
Bleeding complication with dual antiplatelet therapy: spontaneous uvula hematoma
}

\author{
Nicholas G. Kounis MD PhD, Periklis Davlouros MD PhD
}

\begin{abstract}
Competing interests: None declared.

This article has been peer reviewed.

The authors have obtained patient consent.
\end{abstract}

Affiliation: Department of Cardiology, University of Patras Medical School,

Patras, Rio, Achaia, Greece

\section{Correspondence to:}

Nicholas Kounis,

ngkounis@otenet.gr

CMAJ 2014. DOI:10.1503 /cmaj.140270
1 n 81-year-old man with a history of coronary artery disease experienced a sudden choking feeling, sore throat, difficulty swallowing and itchy mouth immediately after finishing dinner. He was taking clopidogrel $75 \mathrm{mg}$ combined with $100 \mathrm{mg}$ acetylsalicylic acid once daily, and metoprolol tartrate $50 \mathrm{mg}$ twice daily for secondary prevention following stent implantation 12 months earlier. On examination in the emergency department, a round dark-coloured structure resembling a foreign body was observed at the back of his mouth. Laryngoscopy identified an enlarged and bruised uvula (Figure 1). Hematocrit, platelet count and activated thromboplastin time were normal. We diagnosed uvula hematoma, and advised the patient to stop antiplatelet treatment and to avoid swallowing hard food. The hematoma disappeared gradually within three weeks, and there was no recurrence after he started monotherapy with acetylsalicylic acid.

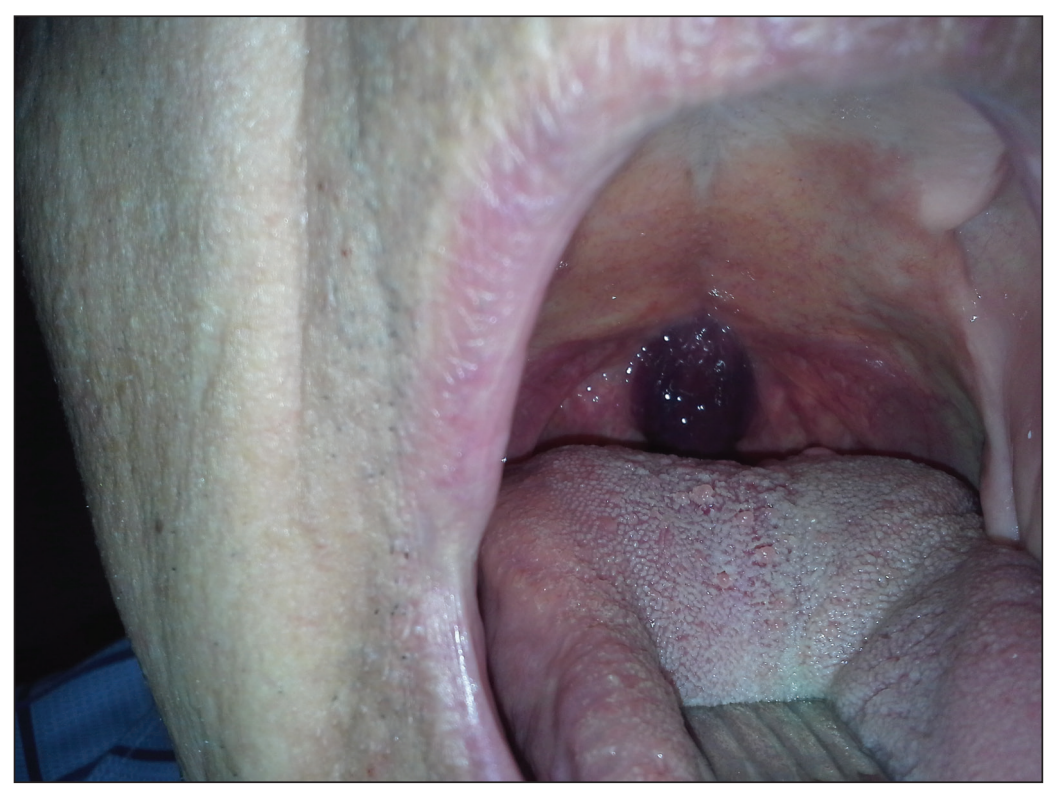

Figure 1: Enlarged and bruised uvula in an 81-year-old man taking dual antiplatelet therapy.
Dual antiplatelet therapy has been associated with bleeding in $3 \%$ of patients during the first six months of treatment and in $5.5 \%$ of patients by the end of the first year. ${ }^{1}$ In a large retrospective cohort study, the rate of major bleeding at 30 days of treatment, defined as intracranial bleeding or bleeding associated with a hematocrit decrease of at least $15 \%$, was estimated at 14.3 per 100 person-years. ${ }^{2}$ Risk factors for major bleeds include age greater than 75 years, liver disease, gastrointestinal disease and prior stroke. ${ }^{3}$ The most common sites of bleeding are gastrointestinal, intracranial and urinary. ${ }^{4}$ In some cases, treatment may require intravenous fluids, transfusion, antifibrinolytics and, rarely, surgical or endoscopic procedures. ${ }^{4}$ Caution is warranted in stopping both antiplatelet agents, because this has been associated with an increase in major cardiovascular events. ${ }^{4}$

Uvula hematoma has been previously described in relation to streptokinase therapy and endotracheal intubation. ${ }^{5}$ Our patient's hematoma could have been precipitated by trauma related to eating hard crackers.

\section{References}

1. Zhang L, Li Y, Jing QM, et al.; CREATE investigators. Dual antiplatelet therapy over 6 months increases the risk of bleeding after biodegradable polymer-coated sirolimus eluting stents implantation: insights from the CREATE Study. J Interv Cardiol 2014;27:119-26.

2. Lamberts M, Olesen JB, Ruwald MH, et al. Bleeding after initiation of multiple antithrombotic drugs, including triple therapy, in atrial fibrillation patients following myocardial infarction and coronary intervention: a nationwide cohort study. Circulation 2012;126:1185-93.

3. Berger PB, Bhatt DL, Fuster V, et al.; CHARISMA investigators. Bleeding complications with dual antiplatelet therapy among patients with stable vascular disease or risk factors for vascular disease: results from the Clopidogrel for High Atherothrombotic Risk and Ischemic Stabilization, Management, and Avoidance (CHARISMA) trial. Circulation 2010;121:2575-83.

4. Mehran R, Baber U, Steg PG, et al. Cessation of dual antiplatelet treatment and cardiac events after percutaneous coronary intervention (PARIS): 2 year results from a prospective observational study. Lancet 2013;382:1714-22.

5. Kayrak M, Ulgen MS, Yazici M, et al. Uvula haematoma: a rare complication after thrombolysis and intensive anti-platelet treatment. Ann Card Anaesth 2007;10:140-1. 